\title{
Toward validating the Italian version of the "Spanish Burnout Inventory": a preliminary study
}

\author{
Validação da versão italiana do "Spanish Burnout Inventory": um estudo preliminar \\ Validación de la versión italiana del "Spanish Burnout Inventory": un estudio preliminar
}

Sara Viotti ${ }^{1}$, Pedro R. Gil-Monte ${ }^{2}$, Daniela Converso ${ }^{1}$

${ }^{1}$ University of Turin, Department of Psychology, Turin, Italy.

2 University of Valencia, Department of Psychology, Valencia, Spain.

\begin{abstract}
Objective: The aim of this study was to develop the Italian version of the Spanish Burnout Inventory (SBI) and to examine its psychometric properties within a sample of nursing staff. Method: The study was cross-sectional and not randomized. The data were gathered using an anonymous, self-report questionnaire. The sample consisted of 391 staff nurses employed in three hospitals in the Northern Region of Italy. To evaluate burnout, the SBI and the Maslach Burnout Inventory were administered. Results: An Exploratory Factor Analysis showed a four-factor structure close to the expected one. All Cronbach's alpha values were satisfactory. Furthermore, correlations support the concurrent validity. Conclusion: Overall, the results of this study provided evidence that the SBI is an adequate instrument to study burnout in the Italian nursing sample and indicated the feeling of guilt as an important dimension to gauge the structure of this
\end{abstract} phenomenon.

DESCRIPTORS

Burnout, Professional; Nursing Staff; Psychometrics; Validation Studies. 


\section{INTRODUCTION}

One of the most important psychosocial risks in the health sector is occupational burnout, a psychological response to chronic work-related stress of an interpersonal and emotional nature that appears in professionals working directly with clients or end-users of care services. Specifically in this sector, some studies have pointed out that approximately $8 \%$ of the cases of occupational illness refer to burnout symptoms ${ }^{(1)}$ and that nursing is one of the occupations with the highest burnout prevalence rates ${ }^{(2)}$. The symptoms of burnout can cause repercussions on an individual's health, such as cortisol dysregulation ${ }^{(3)}$, physical symptoms ${ }^{(4)}$, and psychological disorders, such as depression ${ }^{(5)}$. Burnout also has an impact on the organizational level, causing, for instance, absenteeism ${ }^{(6)}$, turnover intention ${ }^{(7)}$, and poor job performance ${ }^{(8)}$. In addition, many studies have shown that job burnout influences the quality of care and patient satisfaction ${ }^{(9)}$. These findings altogether highlight the importance for health sector organizations to monitor job burnout among nurses to foster both healthy work conditions and the quality of the care service ${ }^{(10)}$.

The most widely used instrument to assess burnout is the Maslach Burnout Inventory (MBI) ${ }^{(11)}$. It considers three main symptoms that are assessed by means of the homonymous sub-scales: emotional exhaustion, depersonalization, and personal accomplishment.

The MBI was adopted in more than $90 \%$ of the studies carried out ${ }^{(12)}$. However, many studies have highlighted several limitations. One is that the MBI overlooks many symptoms highlighted in the literature as crucial to the development of burnout syndrome. Examples of these symptoms are physical exhaustion, guilt, and loss of job motivation $^{(13)}$.

Moreover, from a strictly psychometric point of view, many studies did not find support for the three-dimensional factor structure of the $\mathrm{MBI}^{(14)}$ and pointed out that some items loaded on more than one factor ${ }^{(15)}$. This problem can be due to both cultural and lexical factors. Indeed, the MBI was developed in the USA and, in other cultural contexts, its suitability may be poor. For example, North Americans are be more prone than other cultures to give extreme answers to items or to express cynicism in public ${ }^{(16)}$. Therefore, while in a survey involving US workers, it could be appropriate to include an item such as "I don't really care what happens to some recipients" to measure depersonalization, in Latin countries (both in the South of Europe and America), the same item could be problematic, exposing a social desirability bias.

The Spanish Burnout Inventory (SBI) ${ }^{(17)}$ was developed with the aim of overcoming these problems. The theoretical model underlying the SBI is based on the concept that burnout is a response to chronic job stress that stems from problematic interpersonal work relationships. It is characterized by cognitive deterioration (i.e., low enthusiasm toward the job), emotional deterioration (i.e., psychological exhaustion), attitudes and behaviors of indifference, indolence, withdrawal, and, in some cases, feelings of guilt.
The research process which led to the development of SBI progressed through two main stages. In the first stage, a qualitative-exploratory study was carried out. As a result of a series of semi-structured interviews, 74 symptoms which describe the syndrome were identified. Hence, corresponding items were formulated and their functioning was evaluated during the second stage, called quantitativepsychometric. This was achieved by various studies involving different professional categories from health, social and educational sectors. At this level, the items which displayed criticality from the psychometric and the content point of view were gradually discarded, until the final version of SBI was achieved. This comprises 20 items divided into four sub-scales: enthusiasm towards the job: the individual's desire to achieve goals at work as a source of personal pleasure; psychological exhaustion: the appearance of emotional and physical exhaustion due to the fact that front-line workers have to deal with "problematic" people on a daily basis; indolence: the appearance of negative attitudes of indifference and cynicism towards the organization's clients; guilt: the appearance of feelings of guilt about negative attitudes developed on the job, especially towards the people with whom staff establishes work relationships.

The research process that led to the development of the SBI progressed through two main stages. In the first stage, a qualitative-exploratory study was carried out. As a result of a series of semi-structured interviews, 74 symptoms that describe the syndrome were identified. Hence, corresponding items were formulated and their functioning was evaluated during the second stage, called quantitativepsychometric. This was achieved by various studies involving different professional categories from the health, social, and educational sectors. At this level, the items that displayed criticality from the psychometric and the content points of view were gradually discarded until the final version of the SBI was achieved. This comprises 20 items divided into four sub-scales:

Enthusiasm toward the job: the individual's desire to achieve goals at work as a source of personal pleasure;

Psychological exhaustion: the appearance of emotional and physical exhaustion due to the fact that frontline workers have to deal with "problematic" people on a daily basis.

Indolence: the appearance of negative attitudes of indifference and cynicism toward the organization's clients;

Guilt: the appearance of feelings of guilt about negative attitudes developed on the job, especially toward the people with whom staff establishes work relationships.

Enthusiasm toward to the job, psychological exhaustion, and indolence are similar, respectively, to personal accomplishment, emotional exhaustion, and depersonalization from the MBI. On the contrary, guilt represents an original dimension of the SBI.

The feeling of guilt is a symptom that has already been identified as typical of burnout syndrome by Maslach ${ }^{(18)}$, Freudenberg ${ }^{(19)}$, and many other recent studies ${ }^{(13)}$. However, the SBI is the only instrument available in the literature that includes guilt. Guilt can be defined as an unpleasant 
and remorseful feeling related to recognizing that one has violated, or is capable of violating, a moral standard. Feelings of guilt, especially in health professions, can appear because of negative thoughts about others, of negative and cynical ways of treating clients/patients, and of feeling conflicted about several ethical issues ${ }^{(20)}$. Guilt might cause or reinforce feelings of powerlessness and hopelessness, and, over time, guilt may lead to more serious psychological health issues, such as depression ${ }^{(21)}$.

The model underlying the SBI distinguishes two profiles in the development of burnout. In both, indolent attitudes and behaviors can be understood as coping strategies to handle emotional and cognitive deterioration. Profile 1 describes individuals who suffer moderately from burnout. Indolence represents an adequate coping strategy for these workers, allowing them to manage the levels of strain. Despite the presence of symptoms (low enthusiasm, high exhaustion, and indolence), the individual in this profile is still able to work and does not show feelings of guilt. Conversely, people in Profile 2 develop a more severe stress reaction, mostly because indolence is in this case an inadequate coping strategy, and feelings of guilt may appear. These individuals have difficulty in carrying out their job appropriately and are more prone to unplanned absences from work.

Factorial validity of the four-factor structure model of the SBI, as well as the internal consistency and concurrent validity between the SBI and the MBI, has been demonstrated in previous research studies conducted within different professional groups and in several Latin countries. In particular, empirical evidence about the psychometric characteristics of the SBI was provided in the following samples: (a) professionals working with disabled people $\mathrm{e}^{(17)}$, (b) physicians $^{(22)}$, (c) prison employees ${ }^{(23)}$, and (d) nurses and teachers $^{(24)}$.

In all these studies, the item-factor relationships were satisfactory; the lowest values were obtained for item 11 (I feel like being sarcastic with some patients) in the indolence scale in study $(\mathrm{a})^{(22)}(\lambda=.25)$ and for item 14 (I label or classify students according to their behavior) $(\lambda=.31)$ in study $(\mathrm{d})^{(23)}$, belonging to the same scale. Moreover, in all studies, the score reliability of the sub-scales displays acceptable values (above .70). With regard to the concurrent validity, the correlations between, respectively, enthusiasm toward the job (SBI) and personal accomplishment (MBI), psychological exhaustion (SBI) and emotional exhaustion (MBI), and indolence (SBI) and depersonalization (MBI) were significant.

The aim of this study was to develop the Italian version of the SBI and to examine its psychometric properties within a sample of nursing staff.

\section{METHOD}

\section{Settings And SAMPLE}

The study design was cross-sectional and not randomized. In 2012, an agreement for an Occupational Health
Surveillance Program aimed at monitoring nursing staff health was developed between the Department of Psychology (University of Turin) and three hospitals in Piedmont (a northern region in Italy). All nurses that have to participate in a physical examination in the workplace (mandatory by Italian law once a year for workers in the health sector) during the period of March-September 2012 were considered for the present study.

\section{ETHICAL CONSIDERATION}

Hospital administrations evaluated, endorsed, and authorized the research, allowing researchers to use the data for scientific purposes. Participants volunteered in the research without receiving any reward; they signed the informed consent and agreed to complete anonymously a questionnaire. An additional ethical approval was not required, as there was no treatment, including medical, invasive diagnostics, or procedures causing psychological or social discomfort for the participants. As well, no patients were involved in the data collection. The research conforms to the provisions of the Declaration of Helsinki in 1995 (as revised in Edinburgh 2000) and all ethical guidelines were followed as required for conducting human research, including adherence to the legal requirements of the study country (Italy).

\section{INSTRUMENTS}

To develop the Italian version, the International Test Commission (ITC) methodological criteria for the adequate adaptation of instruments to other cultures ${ }^{(25)}$ were followed. Specifically, the items in the SBI scale were translated from Spanish into Italian by a professional translator and approved by two academic experts in the burnout and psychometric fields (the first was an Italian mother tongue who speaks Spanish and the second, a Spanish mother tongue who speaks Italian). The SBI was then back translated by another professional translator. The two versions thus obtained were compared, discussed, and reviewed until a complete agreement was reached among the translators and the experts.

The questionnaire consisted of 20 items distributed in four scales (five-point scale ranging from 0 "Never" to 4 "Everyday"): enthusiasm toward the job (5 items, e.g., I see my job as a source of personal accomplishment), psychological exhaustion (4 items, e.g., I feel emotionally exhausted), indolence (6 items, e.g., I don't like taking care of some patients), and guilt (5 items, e.g., I regret some of my behaviors at work). Low scores on enthusiasm toward the job, together with high scores on psychological exhaustion, indolence, and guilt indicate a high level of burnout.

Burnout syndrome was also assessed by using the Italian adaptation of the Maslach Burnout Inventory-Human Service Survey ${ }^{(11,26)}$. This instrument consists of 22 items distributed on three scales (seven-point frequency scale ranging from 0 "Never" to 6 "Everyday"): personal accomplishment (8 items), emotional exhaustion (9 items), and depersonalization (5 items). Low scores on personal accomplishment, 
together with high scores on emotional exhaustion and depersonalization, correspond to high levels of burnout.

\section{Data collection}

Nurses, after the physical examination, had a meeting with a psychologist who asked them to fill out a self-report questionnaire.

In total, 556 nurses were reached, where 391 nursing staff correctly filled out the questionnaires that were used for this study (response rate: about 70\%).

The sample consisted of 391 staff nurses from three hospitals (Hospital 1: 55\%; Hospital 2: 34\%; Hospital 3: 11\%). Concerning gender, 93 participants were men (23.8\%) and 298 were women $(76.2 \%)$. The mean age of the participants in the study was 40.41 years $(\mathrm{SD}=9.26$, min. $=24$ years, $\max .=63$ years $)$ and the average length of service in the health sector was 14.99 years $(\mathrm{SD}=9.97)$. With regard to the type of contract, 359 (89\%) participants were permanent workers and only 19 (10\%) were temporary.

\section{DAtA ANALYsis}

Data analyses were performed using the Statistical Package for Social Sciences (SPSS) version 21 and were completed in four steps: a) item analysis (mean, standard deviation, skewness, and kurtosis); b) assessment of score reliability of the SBI sub-scales (Cronbach's alpha and alpha if item is deleted); c) testing factorial validity of the SBI by Exploratory Factor Analysis (EFA, Principal Component Analysis; Method of Estimation: Maximum Likelihood; Rotation method: Varimax); and d) Pearson's correlation between the SBI and MBI sub-scales to assess concurrent validity.

\section{RESULTS}

\section{ITEM ANALYSIS}

Descriptive statistics for the items are shown in Table 1. The highest mean values were reached by the items that belong to the enthusiasm toward the job scale, as characterized by high scores indicating low levels of burnout.

For most items, the corrected item-total correlation achieved values equal or greater than $r=.40$, but the values for items 6 (I think that relatives of patients are very demanding) and 11 (I feel like being sarcastic with some patients), which belong to the indolence scale, were .30 and .33 , respectively. With regard to the skewness, items from the enthusiasm toward the job scale reflected a negative value and, thus, there was a tendency toward high-range scores. In contrast, the opposite tendency occurred with the remaining sub-scales, except for items 12 and 17 in the psychological exhaustion scale and item 6 in the indolence scale. All values of skewness and kurtosis are comprised in the range -1.0 to +1.0 . Therefore, normal theory estimation could be appropriate for examining the underlying factor structure and not much distortion is to be expected.

\section{INTERNAL CONSISTENCY}

Regarding the internal consistency, all values of Cronbach's alpha in the SBI were higher than .70 (Table 1):
Enthusiasm towards the job ( $\alpha=.86)$, Psychological exhaustion $(\alpha=.85)$, Indolence $(\alpha=.72)$, and Guilt $(\alpha=.85)$. Regarding the Cronbach's alpha values from MBI scales, Personal accomplishment $(\alpha=.80)$ as well Emotional exhaustion $(\alpha=.89)$ were satisfactory. Concerning Depersonalization, the value was lower than .70 $(\alpha=.69)$.

Table 1 - Descriptive Statistics of SBI Items - Turin, Italy, 2014.

Subscale
Item $\quad \mathrm{M}(\mathrm{SD}) \quad \begin{gathered}\text { Corrected } \\
\text { item-scale } \\
\text { correlations }\end{gathered}$ Skewness Kurtosis \begin{tabular}{c}
$\begin{array}{c}\text { Alpha if } \\
\text { item is } \\
\text { deleted }\end{array}$ \\
\hline
\end{tabular}

Enthusiasm toward the job $(\alpha=.86)$

\begin{tabular}{lccccc}
1 & $2.49(.98)$ & .61 & -.45 & .10 & .85 \\
5 & $2.53(1.12)$ & .70 & -.49 & -.40 & .83 \\
10 & $2.75(.91)$ & .67 & -.64 & .52 & .83 \\
15 & $2.67(.98)$ & .73 & -.65 & .38 & .82 \\
19 & $2.61(.98)$ & .69 & -.61 & .60 & .83 \\
\hline
\end{tabular}

Psychological exhaustion $(\alpha=.85)$

\begin{tabular}{llllll}
8 & $1.75(1.10)$ & .66 & .01 & -.65 & .82 \\
12 & $2.07(1.10)$ & .65 & -.12 & -.38 & .82 \\
17 & $2.17(1.06)$ & .71 & -.17 & -.26 & .80 \\
18 & $1.95(1.11)$ & .72 & .07 & -.54 & .79 \\
\hline
\end{tabular}

Indolence $(\alpha=.72)$

\begin{tabular}{lccccc}
2 & $1.34(.99)$ & .46 & .30 & -.38 & .67 \\
3 & $1.65(.94)$ & .54 & .36 & .26 & .65 \\
6 & $2.43(.99)$ & .30 & -.16 & -.21 & .72 \\
7 & $.90(.97)$ & .56 & .89 & .22 & .64 \\
11 & $1.38(1.26)$ & .33 & .46 & -.88 & .72 \\
14 & $1.10(1.02)$ & .54 & .58 & -.43 & .64 \\
\hline
\end{tabular}

Guilt $(\alpha=.85)$

$\begin{array}{lccccc}4 & 1.72(1.20) & .40 & .18 & -.89 & .84 \\ 9 & 1.10(.95) & .69 & .69 & .18 & .74 \\ 13 & .92(.96) & .69 & .98 & .54 & .74 \\ 16 & 1.05(.93) & .61 & .68 & .27 & .77 \\ 20 & .95(.91) & .65 & .90 & .87 & .75\end{array}$

Note 1- Item number indicates the position of the item in the questionnaire. Note 2-The SBI was applied in the Italian language.

\section{EXPLORATORY FACTOR AnAlysis (EFA)}

The Kaiser-Meyer-Olkin measure $(\mathrm{KMO}=.85$, greater than .70) and Bartlett's test of sphericity test $(\mathrm{p}<.05)$ indicate that the factor model is appropriate (suggesting that the sampling is adequate and correlation matrix is an identity matrix).

In accordance with the SBI model, using the KaiserGuttman criterion (eigenvalue greater than one), the factor solution showed four factors underlying the 20 items. Overall, the amount of variance explained is $60.09 \%$. Table 2 presents the rotated loadings on the four factors. After rotation, the first factor explained $16.74 \%$ of the variance. It comprises five items of enthusiasm toward the job. All items were positively loaded, mostly greater than .40 (the lowest value is on item 1 , which was .75). The second factor was guilt, explaining $15.65 \%$ of the variance. All loadings were greater than .40 and the lowest loading was reached 
by item 4 with a value of .46 . The percentage of variance explained by the third factor was 15.45. In this factor, all items of psychological exhaustion are included. The lowest loading was obtained by item 8 with a value equal to .70 , with the highest being by item 17 , at .85 . The last factor extracted, which explains $12.24 \%$ of the variance, was indolence. The highest value was obtained by item 7 , and the lowest loading was reached by item 6 (.42). Moreover, items 3 and 6 showed a relatively high loading on psychological exhaustion.

Table 2 - Factors, items loading, variance explained of SBI - Turin, Italy, 2014.

\begin{tabular}{|c|c|c|c|c|}
\hline \multirow{2}{*}{ Item } & \multicolumn{4}{|c|}{ Factors } \\
\hline & Factor I & Factor II & Factor III & Factor IV \\
\hline 1 & .75 & .02 & -.03 & .06 \\
\hline 5 & .83 & .04 & -.03 & -.01 \\
\hline 10 & .80 & .02 & -.06 & -.01 \\
\hline 15 & .81 & .02 & -.13 & -.14 \\
\hline 19 & .78 & .08 & -.14 & -.09 \\
\hline 8 & -.15 & .27 & .70 & .21 \\
\hline 12 & -.12 & .18 & .73 & .11 \\
\hline 17 & -.11 & .05 & .85 & -.01 \\
\hline 18 & -.09 & .22 & .82 & .05 \\
\hline 2 & -.08 & .11 & .27 & .61 \\
\hline 3 & -.05 & .00 & .43 & .64 \\
\hline 6 & .21 & -.17 & .50 & .42 \\
\hline 7 & -.05 & .34 & .04 & .71 \\
\hline 11 & .04 & .25 & -.11 & .54 \\
\hline 14 & -.12 & .32 & .04 & .67 \\
\hline 4 & .26 & .46 & .19 & .08 \\
\hline 9 & .01 & .78 & .19 & .18 \\
\hline 13 & -.02 & .79 & .12 & .22 \\
\hline 16 & .06 & .78 & .03 & .15 \\
\hline 20 & -.00 & .76 & .11 & .20 \\
\hline$\%$ of Variance & $16.74 \%$ & $15.65 \%$ & $15.45 \%$ & $12.24 \%$ \\
\hline
\end{tabular}

Note 1- Bold type indicate Value $\geq .40$.

\section{Concurrent VAlidity}

To estimate concurrent validity, Pearson's correlations were performed. In Table 3, correlations among the four dimensions of the SBI with the three dimensions of the MBI are displayed: the correlation between enthusiasm toward the job and personal accomplishment was $r=.36$ $(\mathrm{p}<.001)$, between psychological exhaustion and emotional exhaustion was $r=.71(p<.001)$, and, finally, between indolence and depersonalization was $r=.52(p<.001)$. Therefore, it could be concluded that they are measuring similar constructs.

\section{DISCUSSION}

The purpose of this study was to examine the psychometric properties of the Italian version of the SBI. Ba- sed on the findings, the results obtained indicate that the psychometric properties of this inventory are adequate in the study sample.

The corrected item-scale correlation values obtained for the items are relatively high ${ }^{(27)}$; this indicates that each dimension of the SBI can be considered as a linear function of the items that make it up. Furthermore, the internal consistencies of the four dimensions were satisfactory ${ }^{(28)}$, with all Cronbach's alphas ranging from .72 to .86. These results are similar to those reported in previous studies conducted in other countries, such as Mexico ${ }^{(23)}$ and Portugal ${ }^{(24)}$.

Table 3 - Correlation between dimension of SBI and with dimension of MBI - Turin, Italy, 2014.

\begin{tabular}{lccc}
\hline & $\begin{array}{c}\text { Personal } \\
\text { Accomplishment }\end{array}$ & $\begin{array}{c}\text { Emotional } \\
\text { Exhaustion }\end{array}$ & Depersonalization \\
\hline $\begin{array}{l}\text { Enthusiasm } \\
\text { toward the job }\end{array}$ & $.36^{*}$ & $-.29^{*}$ & $-.17^{* *}$ \\
$\begin{array}{l}\text { Psychological } \\
\text { exhaustion }\end{array}$ & $-.17^{* *}$ & $.71^{*}$ & $.32^{*}$ \\
Indolence & $-.23^{*}$ & $.38^{*}$ & $.59^{*}$ \\
Guilt & $-.15^{* *}$ & $.31^{*}$ & $.39^{*}$ \\
\hline Note $3-^{*} \mathrm{p}<.01,{ }^{* *} \mathrm{p}<.05$ & & &
\end{tabular}

Concerning factorial validity, it can be affirmed that the factorial model adequately reproduces the theoretical model of the SBI and its four underlying dimensions: enthusiasm toward the job, psychological exhaustion, indolence, and guilt. Moreover, guilt is the second extracted dimension and it explains a significant portion of the variance (15.65\%); this result confirms that the feeling of guilt, never taken into consideration by any tool aimed at assessing burnout, is an important dimension that helps to better understand and capture the phenomenon.

Nevertheless, three items require comments. Items 6 (I think that relatives of patients are very demanding) and 11 (I feel like being sarcastic with some patients) presented the lowest item sub-scale relationship, even if not lower than $.30^{(27)}$. Only a few previous studies, using Confirmatory Factor Analysis, have reported item 6 as problematic ${ }^{(29)}$. This could be because the items in the indolence sub-scale refer to the relationship with patients, while item 6 investigates the relationship with relatives. Moreover, in this study, item 6 displays a not-entirely insignificant loading on psychological exhaustion. This aspect has never emerged before. Further studies could contribute to shedding some light on the functioning of this item within the SBI and to clarifying whether this is a sample-specific problem or if this concerns specifically the Italian version of the SBI.

In contrast, the low item-scale correlations between item 11 and indolence have also been found in previous studies ${ }^{(21,26)}$. This result could also be related specifically to the term sarcastic, whose corresponding term in Italian ("sarcastico") may be interpreted in a negative manner, fostering a social desirability bias more than in the English or Spanish languages.

The concurrent validity of the SBI was obtained through correlations with the parallel sub-scale of the MBI: enthu- 
siasm toward the job vs. personal accomplishment, psychological exhaustion vs. emotional exhaustion, and indolence vs. depersonalization. All pairs are significantly associated with the expected direction, which implies that the theoretical construct of burnout estimated by the SBI is similar to those of other major burnout scales. The findings are consistent with other results in the literature ${ }^{(17,23-24)}$.

This study is not without limitations. First, the sample was limited to one Italian region and, second, participants were selected in a non-random way. Therefore, the findings should not be considered representative of the entire country. Third, the data were obtained from nurses' self-reports and, consequently, may reflect a bias in reporting certain feelings. Finally, the sample was mostly composed of women and this, too, might affect results.

\section{CONCLUSION}

The relevance of this study is that it provides evidence for the goodness of the psychometric properties of an alternative burnout measure to the MBI, even in Italian staff nurses, offering a theoretical proposal to explain different types of burnout and taking into account guilt as a symptom of burnout.

An Italian version of the SBI may offer to occupational health researchers, practitioners, and nursing training providers an expanded conceptualization of this syndrome. Moreover, the availability of reliable and valid instruments to measure burnout has a crucial importance in helping healthcare management to determine the dimension of the problem inside an organization and to prevent it and its consequences through appropriate intervention programs. The SBI has been used with some Brazilian samples-although never among nursing staff-to provide results that conformed to the four-factor theoretical structure.

Several recommendations for further studies could be provided. Concerning the Italian version of the SBI, cut-off scores on each dimension of burnout should be identified to determine the incidence and the prevalence of the phenomenon among nurses. Moreover, future studies should analyze the construct equivalence of the factorial invariance of the four-factor model of the SBI across different speaking samples (for example, Spanish, Portuguese, and Italian).

\section{RESUMO}

Objetivo: O objetivo deste estudo foi desenvolver a versão italiana do SBI (Spanish Burnout Inventory) e analisar as suas propriedades psicométricas numa amostra de enfermeiros. Método: O estudo foi de caráter transversal, e não randomizado. Os dados foram coletados através de um questionário autopreenchido de maneira anônima. A amostra foi composta por 391 enfermeiros funcionários de três hospitais de uma região do norte da Itália. Para avaliar o burnout, utilizou-se o Spanish Burnout Inventory e o Maslach Burnout Inventory. Resultados: Os resultados da Análise Fatorial Exploratória mostraram uma estrutura de quatro fatores, como era esperado. Todos os valores de alfa de Cronbach foram satisfatórios. Além disso, as correlações apoiar validade concorrente. Conclusão: No geral, os resultados deste estudo forneceram evidências de que o SBI é um instrumento adequado para estudar o burnout numa amostra de enfermagem italiana e indicou que os sentimentos de culpa são uma dimensão importante para avaliar a estrutura do fenômeno.

\section{DESCRITORES}

Esgotamento Profissional; Recursos Humanos de Enfermagem; Psicometria; Estudos de Validação.

\section{RESUMEN}

Objetivo: Desarrollar la versión italiana del Spanish Burnout Inventory (SBI) y analizar sus propiedades psicométricas en una muestra de enfermeros. Método: Estudio de carácter transversal y no randomizado. Los datos fueron recogidos mediante un cuestionario autorrellenado de manera anónima. La muestra estuvo compuesta de 391 enfermeros funcionarios de tres hospitales de una zona del norte de Italia. A fin de evaluar el burnout, se empleó el Spanish Burnout Inventory y el Maslach Burnout Inventory. Resultados: Los resultados del Análisis Factorial Exploratorio mostraron una estructura de cuatro factores, como era esperado. Todos los valores de alfa de Cronbach fueron satisfactorios. Además, las correlaciones apoyaron la validez concurrente. Conclusión: Los resultados de este estudio proporcionaron evidencias de que el SBI es un instrumento adecuado para estudiar el burnout en una muestra de enfermería italiana y señaló que los sentimientos de culpa son una dimensión importante para evaluar la estructura del fenómeno.

\section{DESCRIPTORES}

Agotamiento Profesional; Personal de Enfermería; Psicometría; Estudios de Validación.

\section{REFERENCES}

1. Sundin L, Hochwälder J, Bildt C, Lisspers J. The relationship between different work related sources of social support and burnout among registered and assistant nurses in Sweden: a questionnaire survey. Int J Nurs Stud. 2006;44(5):758-69.

2. Demerouti E, Bakker AB, Nachreiner F, Schaufeli WB. A model of burnout and life satisfaction amongst nurse. J Adv Nurs. 2000;32(2):454-64.

3. Bellingrath S, Weigl T, Kudielka BM. Cortisol dysregulation in school teachers in relation to burnout, vital exhaustion, and effort-rewardimbalance. Biol Psychol. 2008;78(1):104-13.

4. Leiter MP. Perception of risk: an organizational model of occupational risk, burnout, and physical symptoms. Anxiety Stress Copin. $2005 ; 18(2): 131-44$.

5. Hakanen JJ, Schaufeli WB, Ahola K. The job demand resources model: a three-year cross-lagged study of burnout, depression, commitment and work engagement. Work Stress. 2008; 22(3):224-41. 
6. Davey MM, Cummings G, Newburn-Cook CV, Lo EA. Predictors of nurse absenteeism in hospitals: a systematic review. J Nurs Manag. 2009;17(3):312-30.

7. Leiter MP, Maslach C. Nurse turnover: the mediating role of burnout. J Nurs Manag. 2009; 17(3):331-9.

8. Bakker AB, Demerouti E, Verbeke W. Using the job demands-resources model to predict burnout and performance. Hum Resour Manage. 2004;43(1):83-104.

9. Ferrara $M$, Converso D, Viotti S. Patient satisfaction and occupational health of workers in hospital care setting: Associations and reciprocity. Health. 2012;5(10):1622-8.

10. Laschinger HKS, Grau AL. Authentic leadership, empowerment and burnout: a comparison in new graduates and experienced nurses. J Nurs Manag. 2013;21(3):541-52.

11. Maslach C, Jackson S. Maslach burnout inventory manual. 2nd ed. Palo Alto (CA): Consulting Psychologists Press; 1986.

12. Shirom A, Melamed S. A comparison of the construct validity of two burnout measures in two groups of professionals. Int J Stress Manage. 2006;13(2):176-200.

13. Schafueli WB, Enzmann D. The burnout companion to study and to practice: a critical analysis. London: Taylor \& Francis; 1998.

14. Densten IL. Re-thinking burnout. J Organ Behav. 2001;22:833-43.

15. Poghosyan L, Aiken LH, Sloane DM. Factor structure of the Maslach Burnout Inventory: an analysis of data from large scale cross-sectional surveys of nurses from eight countries. Int J Nurs Stud. 2009;46(7):894-902.

16. Maslach C, Schaufeli WB, Leiter MP. Job burnout. Annu Rev Psychol. 2001;52:397-422.

17. Gil-Monte PR, Olivares V. Psychometric properties of the "Spanish Burnout Inventory" in Chilean professionals working to physical disabled people. Span J Psychol. 2011;14(1):441-51.

18. Maslach C. Burned-out. Hum Behav. 1976;9(5):16-22.

19. Freudenberg HJ. Staff burn-out. J Soc Issues. 1974;30(1):159-65.

20. Ekstedt M, Fagerberg I. Lived experiences of the time preceding burnout. J Adv Nurs. 2005; 49(1):59-67.

21. Gil-Monte PR. The influence of guilt on the relationship between burnout and depression. Eur Psychol. 2012;17(3):231-6.

22. Gil-Monte PR, Zúñiga-Caballero LC. Validez factorial del "Cuestionario para la Evaluación del Síndrome de Quemarse por el Trabajo" (CESQT) en una muestra de médicos mexicanos. Univ Psychol. 2010;9(1):169-78.

23. Gil-Monte PR, Figueiredo-Ferraz H, Valdez-Bonilla H. Factor analysis of the Spanish Burnout Inventory among Mexican prison employees. Can J Behav Sci. 2013;45(2):96-104.

24. Figueiredo-Ferraz H, Gil-Monte PR, Grau-Alberola E. Psychometric properties of the "Spanish Burnout Inventory" (SBI): adaptation and validation in a Portuguese-speaking sample. Eur Rev Appl Psychol. 2013;63(1):33-40.

25. Muñiz J, Hambleton RK. Adaptación de los tests de unas culturas a otras. Metodol Cienc Comp. 2000;2(2):129-49.

26. Loera B, Converso D, Viotti S. Evaluating the Psychometric Properties of the Maslach Burnout Inventory-Human Services Survey (MBI-HSS) among Italian nurses: how many factors must a researcher consider? PLoS One. 2014;9(12):e114987.

27. Floyd FJ, Widaman K.F. Factor analysis in the development and refinement of clinical assessment instruments. Psychol Assess. 1995;7(3):28699.

28. Nunnally NC. Psychometric theory. New York: McGraw-Hill; 1978.

29. Gil-Monte PR, Noyola Cortés VS. Estructura factorial del Cuestionario para la Evaluación del Síndrome de Quemarse por el Trabajo en maestros mexicanos de educación primaria. Rev Mex Psicol. 2011;28(1):75-84.

Acknowledgments: We are grateful to all nurses who participated in the present research.

Financial support: Grant named Organizational well-being in the health sector (D.G.R. 22-7777) fund by Assessorato alla Sanità, Regione Piemonte, Italy (fund's holder: Daniela Converso). Grant n. PSI2013-48185-R from Ministerio de Economía y Competitividad (MINECO), Spanish Government (fund's holder: Pedro Gil-Monte). 